DOI: $10.19195 / 2084-5065.44 .5$

\title{
From experts practice of revealing obliterated and obscured notes and signatures
}

\author{
NiKOLAY BODROV \\ Institute of the Forensic Examinations \\ Kutafin Moscov State Law University (MSAL), Russia
}

The aim for technical and criminalistics examination to detect the original content of invisible and poorly visible notes is not particularly new, as a rule. The methods of identifying faded texts and poorly visible notes have been described by Evgeniy Burinsky in the "Forensic examination of documents, the production and use of it", where he pointed the case of applying the method of colour separation to restore the faded texts of the XIV century, made of the rawhide ${ }^{1}$. The ways of solving this kind of problems got enough coverage in terms of the theory and expert practice. But in recent times we can argue about the circumstances, which make it possible to look at some new aspects of identification the original content of such notes. In our opinion, this includes:

- contemporary possibilities of graphic editors, which are used to illustrate the results of the research documents;

- contemporary possibilities of technical means, which are used to research the documents;

1 Буринский Е.Ф. Судебная экспертиза документов, производство ее и пользование ею. - М.:ЛексЭст, 2002. 
- the tendency of problems convergence of the two expert specialties: the research of handwriting and signature (handwriting analysis) and research of the requisites of documents (technical and forensic examination of documents).

- In practice, all three circumstances are implemented in a single act of expert appraisal, in which there are questions about what the original content of the notes is and by whom they were made?

- In this article, we will analyze two cases from our forensic practice of solving such problems.

- In the first case the document which was presented for the research contained the dashes which were partially blurred from the surface of the document (ill. 1). As it followed from the case files, the documents were discovered in a flooded apartment.

11. Настоящий договор и переход права собственности по нему подлежат государственной регистрации в подразделении Федеральной службы государственной регистрации, кадастра и картографии по Москве.

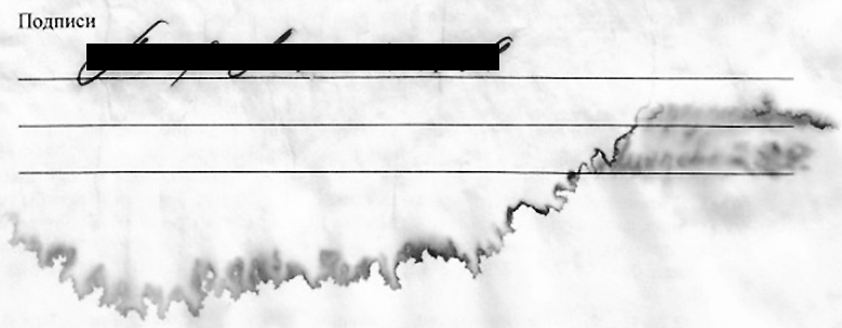

Illustration 1. Part of questioned document

The research of infrared luminescence using a Video Spectral Comparator Foster+FreemanVSC 400 became the most effective way to identify the blurred dashes, however, we had to reduce the intensity of the luminescence by hardware (by closing the diaphragm), because the halos of blurred colouring matter luminesced much stronger, making it difficult to perceive the configuration of the note's dashes.

In some cases, a positive effect could be obtained by masking luminescent areas by previously cut sheets of heavyweight paper or cardboard of different shapes. 


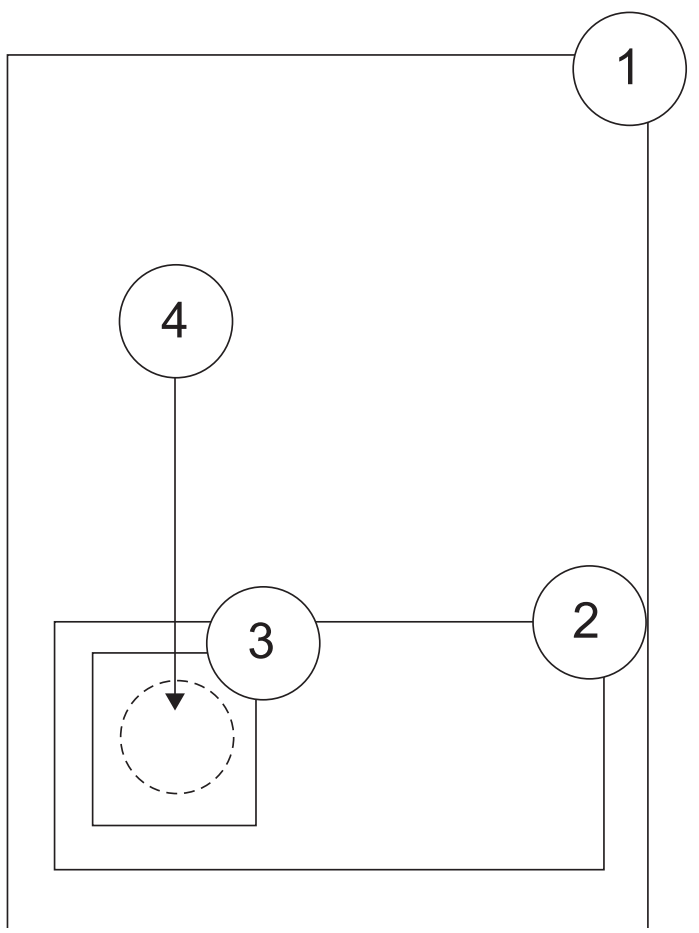

Illustration 2. Document in video spectral comparator

The excessive luminescence of the background is not the last problem, which we faced in the research process. The first difficulty referred to the small size of the working surface of the comparator and the diameter of the beam of light stimulating the luminescence (ill. 2) (In the illustration: $1-$ document paper; 2 - the working surface of the comparator; 3 - the area recorded by the camera; 4 - the area on which beams stimulate the IR-luminescence). To compile the illustrations to the phototable we had to combine pictures into a panorama, however the traditional technique of drawing the panorama up was inapplicable, because parts of the illustrations overlap each other (ill. 3). To prevent mutual overlapping of the images, each of them cut not in the shape of a rectangle, but in the shape which was close to a circle, formed by the light beam of the comparator, and then they were combined by using an optical overlay. The fragment of the final image is shown in the ill. 4. 


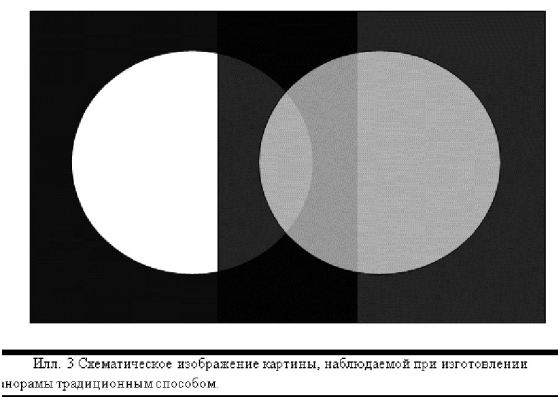

Illustration 3. Schematic illustration of overlap of the images, combined by using traditional technique of making the panorama

As we can see in ill. 4, the analyzed records are painted red. We have to resort to such device for two reasons. Firstly, the digital image processing allows us to differentiate tonal transitions, poorly visible to the human eye, and, secondly, the poor image contrast is further weakened when printing the phototable to the expert findings.

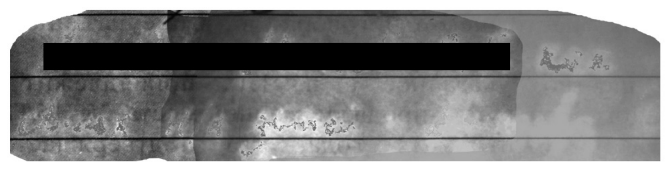

Illustration 4. Part of the panorama made from IR-photos

The technology of coloring the low-contrast dashes was chosen experimentally. It is distinguished by the simplicity and availability of use. In the freeware graphics editor GIMP ${ }^{2}$ there is a function of «contiguous area selection: the selection of neighboring areas according to the similarity of colors» (marked in red in the ill. 5). This function allows you to isolate image areas on the basis of their similarity in colour and brightness contrast. Tuning the parameters of this function's setting "Limit", you can change the sensitivity of the program and get a satisfactory result even with a very small value of the colour/luminance contrast of the dashes.

2 GIMP — The GNU Image Manipulation Program < http://www.gimp.org/> (last visited: 19.12.2016). 


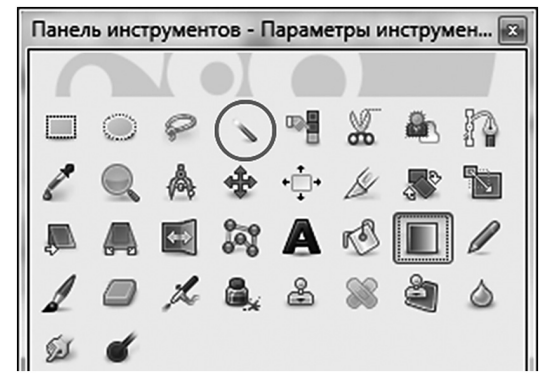

Illustration 5. Part of the menu from GIMP

The necessity to use GNU software (GNU General Public License [GNU GPL or GPL] is a widely used free software license, which guarantees end users the freedom to run, study, share and modify the software) is particularly relevant for experts in handwriting. In Russia there is a large number of experts in handwriting who have not got their own expensive software systems of technical and criminalistics expertise of documents. This problem exists for government experts, who work away from the Federal Centers, which are not always equipped. This problem is even more acute for private experts, who are equipping their laboratories at their own expense.

After described manipulations, we managed to identify and illustrate the contents of the blurred notes, however, we had to abandon from their handwriting research because of the low quality of the image. It is related to the deformation of the pushed-in pen traces because of the effects of water on the document.

Начальнику Управления кадрового администрирования

or

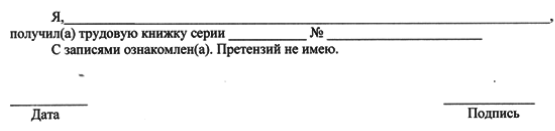

Illustration 6. Questioned document \#2

Nowa Kodyfikacja Prawa Karnego 44, 2017

(C) for this edition by CNS 
In the second case the document looked like a blank without colored dashes was presented for the research (ill.6). Leaving aside the plot of the case, we point out that it was required by an expert way to identify the content of the notes and if possible to identify the personality. Traditional research of bulged-in dashes in oblique illumination for such documents allowed studying the pressure in the dashes, but it didn't give precise information about notes' content. During the research of the document in different lighting conditions in the Video Spectral Comparator it was found that in reflected beams of the ultraviolet radiation with a length of $254 \mathrm{~nm}$ at the location of the blank lines the painted images are observed. Due to the need to identify the initial content we requested the handwriting samples of the estimated person (whose image of the surname note was clearly seen in the reflected UV-beams). This initiative has helped to reliably identify the content, which was especially important, as for example, Russian letter " $\mathrm{x}$ " was performed like letter " $\Pi$ ". The small size of the working surface of the comparator problem was successfully solved by creating a panorama of this photos (I1l. 7). The legibility of the image dashes was increased by traditional methods of changing contrast by forensic photography methods in GIMP graphic redactor.

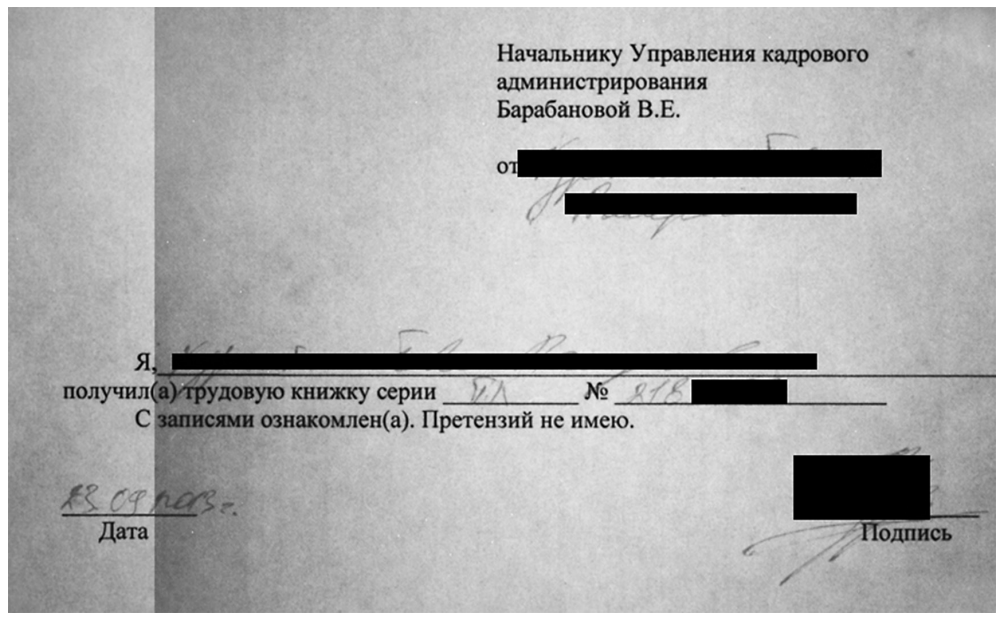

Illustration 7. Revealed notes and signature in questioned document $\# 2$ 
Description of the further conducted handwriting research of the identified notes and signatures requires a certain theoretical understanding. At first glance, we faced a very common problem of the research of images of handwritten details in the copy obtained by the comparator. But the original was presented to the research, and we tried to analyze the pressure characteristics available in the original.

Thus, we get a splitting of the handwriting examination object to the original (which contains the information about the degree and nature of the dash pressure) and a copy (which contains the configuration of the dashes, not seen in the original).

We have overlapped the image obtained in the aslant falling beams at the image produced in the UV-rays. By switching between the layers of two images, we got the opportunity to study the configuration of the dashes, and then the pressure in them.

We were observing the document of research in the reflected aslant falling beams of infrared radiation in order to study the degree and nature of the pressure. Thus, it was possible to monitor the dash pressure in the process of videospectral research. Pressure characteristics were described in the text of the expert findings during the observation. According to the results of the handwriting research, a definitive conclusion about the way of making the notes and the signature of the person on whose behalf they were seemed to be (that man, whose signature and handwriting we requested) has been given.

It should be noted individually that in describing the writing materials of such kind it would be wrong to use "sympathetic ink" term (we met such term in the findings of Russian colleagues). Sympathetic ink implies making the invisible dashes for their further display. From the description of the circumstances of the case, presented to the experts, it was known that the person made the notes and the signature in a statement by a visible writing material but over time it has completely lost colour. To indicate this type of colorants we use the term "ink with chemically unstable pigment".

Thus, the research photographing methods (the research of the documents in the invisible areas of the spectrum) on the one hand, help to identify handwritten notes and signatures, which can then be subjected into handwriting analysis; on the other hand, they contribute the identification 
of the technical features of handwriting reproducing objects and the correct assessment of a number of signs including the nature and degree of pressure.

The situation described above clearly demonstrates the importance of complete simultaneous training of experts in handwriting and technical and criminalistics examination of documents. In some of the state expert institutions and in many private ones there is a strict division into two laboratories: of technical examination of documents and of handwriting research. The separation of these specialties leads to the reduction of categorical conclusions of handwriting experts, to refusing to solve a number of problems, to having the incomplete handwriting research objects in relation to their realization using technical tools and techniques. As the analysis of a number of findings shown presented us for the review, many handwriting experts ignore the steps, involving the use of technical means, considering that these steps relate to the technical examination of the documents. We were faced with the fact that the experts point video spectral comparator and microscope in the list of the used equipment, however, the equipment is almost not used (they do not own it due to very high price). The neglect of this step, as a rule, tends either to beginners, who, because of their little experience, firstly appreciate only catchy features (difficulty, form), without exploring micro features or, conversely, to the unfair experts, who hide behind lots of experience. For example, in one trial, the expert with 20 years of experience stated that she did not need the microscope for research is not necessary, and she has, literally: "The eyes like a microscope for so many years of practice".

Considering the importance of training the specialists of dual competence, in the Institute of the Forensic Examinations of the Kutafin Moscow State University (MSAL) it provides comprehensive education of specialists in the field of documentary research since 2005, and the specialists can equally use methods and equipment for the research of handwritten and other details of the documents.

We hope that the analysis of expert practice examples described in this article will help experts to identify the invisible and poorly visible dashes, to present the research results and to choose their skills development directions. 


\section{References}

Bodrov N.F., Podvolotsky I.N., "To the question of traditional and modern methods of technical forgery of signatures and handwritten notes", Laws of Russia: Experience, Analysis, Practice 12, 2011, pp. 84-89.

Burinsky E.F., Forensic Examination of Documents, Its Production and Use, LexEst, M. 2002.

Dildin U.M., Martynov V.V., Tehniko-criminalistic Examination of Documents, part I. Typical Expert Methods of Research of Material Evidence, Ministry of Internal Affairs of Russia, Moscow 2010.

Technical and Forensic Examination of Documents, eds. V.E. Lyapichev, N.N. Shvedova, Ministry of Internal Affairs of Russia, Volgograd 2005.

The Ministry of Justice of the Russian Federation, Possibilities for the Production of Forensic Expertise in the State Forensic Institutions of the Ministry of Justice of Russia, M. 2004.

\section{Summary}

This article focuses on the analysis of practice, which allows for identification of hidden texts and signatures. The examples of subsequent handwriting researches of detected notes, signatures and people, on whose behalf they were made, are given. In this article there is a description of optical research of dashes, which were created by common and special pens. The author formulated all practical recommendations about working with research equipment, programs and creating illustrations (phototable) to expert testimony. There are several findings: 1) the aggressive impact on the document sometimes does not preclude the successful handwriting identification of the remote notes and signatures perpetrator; 2) based on the outcome of the practice analysis, it points to the need of joining two specialties: «technical and criminalistics examination» and «forensic handwriting examination» due to the fact that practicing experts in the handwriting field often make mistakes.

Keyword: forensic science, questioned documents, forensic handwriting examination, notes, signatures, obliterated, obscured. 